\title{
IMPLEMENTANDO O PROTOCOLO DE CIRURGIA SEGURA EM UM HOSPITAL MUNICIPAL DE URGÊNCIA E EMERGÊNCIA EM SÃO LUÍS-MA: RELATO DE EXPERIÊNCIA
}

\section{Autores: Fabrícia Cavalcante Rocha; Manuela Veiga Dias Rocha; Érica Brandão de Moraes}

\section{INTRODUÇÃO}

O segundo Desafio Global para a Segurança do paciente dirige a atenção para os fundamentos e práticas da segurança cirúrgica, que são, inquestionavelmente, componentes essenciais da assistência à saúde. No entanto, persiste a necessidade de se investir na busca de melhoria da qualidade e garantia de segurança nas intervenções cirúrgicas, que resulte progressivamente em mais vidas salvas e mais incapacidades evitáveis (OMS, 2010).

Em 2013 o Ministério da Saúde(MS) lançou o Protocolo de Cirurgia Segura com a finalidade de determinar as medidas a serem implantadas para reduzir a ocorrência de incidentes e eventos adversos e a mortalidade cirúrgica, possibilitando o aumento da segurança na realização de procedimentos cirúrgicos, no local correto e no paciente correto, por meio do uso da Lista de Verificação de Cirurgia Segura desenvolvida pela Organização Mundial da Saúde ( OMS, 2009) .

\section{OBJETIVO}

O presente trabalho objetiva relatar as experiências e vivências do gestor durante a implementação do protocolo de cirurgia segura.

\section{METODOLOGIA}

\subsection{TIPO DE ESTUDO}

Trata-se de um estudo descritivo, tipo relato de experiência, desenvolvido em um hospital de urgência e emergência municipal.

3.2 LOCAL DO ESTUDO E CONTEXTO ORGANIZACIONAL

O Hospital Socorrão II, foi fundado em 1998, é um hospital público de gestão municipal, localizado na cidade de São Luís capital do Estado do Maranhão. Possui 226 leitos cadastrados e é porta de entrada em urgência e emergência com atendimentos em trauma-ortopedia, cirurgia geral, clínica médica e cirurgia vascular.

Possui habilitação em unidade de alta complexidade em traumatologia e ortopedia, sendo, portanto considerado referência nessa especialidade.

\subsection{DESENVOLVIMENTO}

Em 2015 foi criado o Núcleo de Segurança do Paciente deste hospital e dentro do escopo do trabalho do NSP estava institucionalizar os seis protocolos principais de segurança do paciente de acordo com as orientações gerais do Ministério da Saúde. O núcleo era multiprofissional e o enfermeiro gestor do Centro Cirúrgico (CC) integrava a equipe participando das discussões e planejamento de ações de segurança do paciente.

$\mathrm{O}$ protocolo institucional de cirurgia segura foi elaborado com adaptações para que se aproximasse da realidade da unidade hospitalar onde ele seria implantado.

As frentes de atuação no protocolo contemplavam quatro eixos: Prevenção de infecção do sítio cirúrgico, anestesiologia segura, equipes cirúrgicas eficientes e mensuração da assistência cirúrgica. Para cada eixo foram desenvolvidas atividades e instrumentos para efetivação das ações de segurança.

Após a elaboração do protocolo foi iniciada a fase de treinamento das equipes envolvendo cada eixo do protocolo. Inicialmente foram treinados os líderes médicos (cirurgiões e anestesistas), posteriormente e de forma mais continua a equipe de enfermagem e, também, os agentes administrativos. As reuniões eram lideradas pela enfermeira gestora do CC e aconteciam no auditório do hospital para maior participação dos colaboradores.

$\mathrm{Na}$ fase inicial de implementação o principal foco do treinamento foi o checklist de cirurgia segura. Logo após a fase de apresentação do timeout a formação de valores e comportamento acerca da segurança do paciente que se submete a cirurgia foi sendo densificada com a reestruturação do instrumento da sistematização da assistência perioperatória implantado anteriormente em 2014. O novo instrumento mitigava possíveis incidentes que poderiam causar danos ao paciente.

No ano de 2016 com o intuito de mensurar a produtividade cirúrgica foi elaborado um instrumento de coleta de dados das cirurgias realizadas. Todas informações referentes ao procedimento e as equipes envolvidas são relatadas pelo circulante de sala e posteriormente digitadas numa planilha Excel já que não há sistema informatizado no setor. A coleta de dados é manual e ao final de cada mês é gerado um relatório contendo indicadores de qualidade que auxiliam na gestão do CC.

Em 2017 foi iniciada as discussões sobre o agendamento cirúrgico. Neste mesmo ano foi elaborado o protocolo de antibióticoprofilaxia que foi implementado com apoio da $\mathrm{CClH}$.

Em 2018 o protocolo de cirurgia segura foi atualizado e a principal mudança foi detalhar os papeis de cada integrante da equipe cirúrgica e dos setores fora do CC na implementação da segurança dos procedimentos cirúrgicos.

\section{RESULTADOS}

O processo de implementação do protocolo de cirurgia segura é complexo e requer envolvimento de todas as equipes dentro e fora do centro cirúrgico já que a assistência é continua. Para realizar o acompanhamento do processo através de dados foram realizadas auditorias nos anos de 2017 e 2018 de ações referentes ao protocolo tais como adesão ao checklist de cirurgia segura, adesão a SAEP, qualidade de preenchimento do aviso de cirurgia segura, adesão ao protocolo de antibioticoprofilaxia.

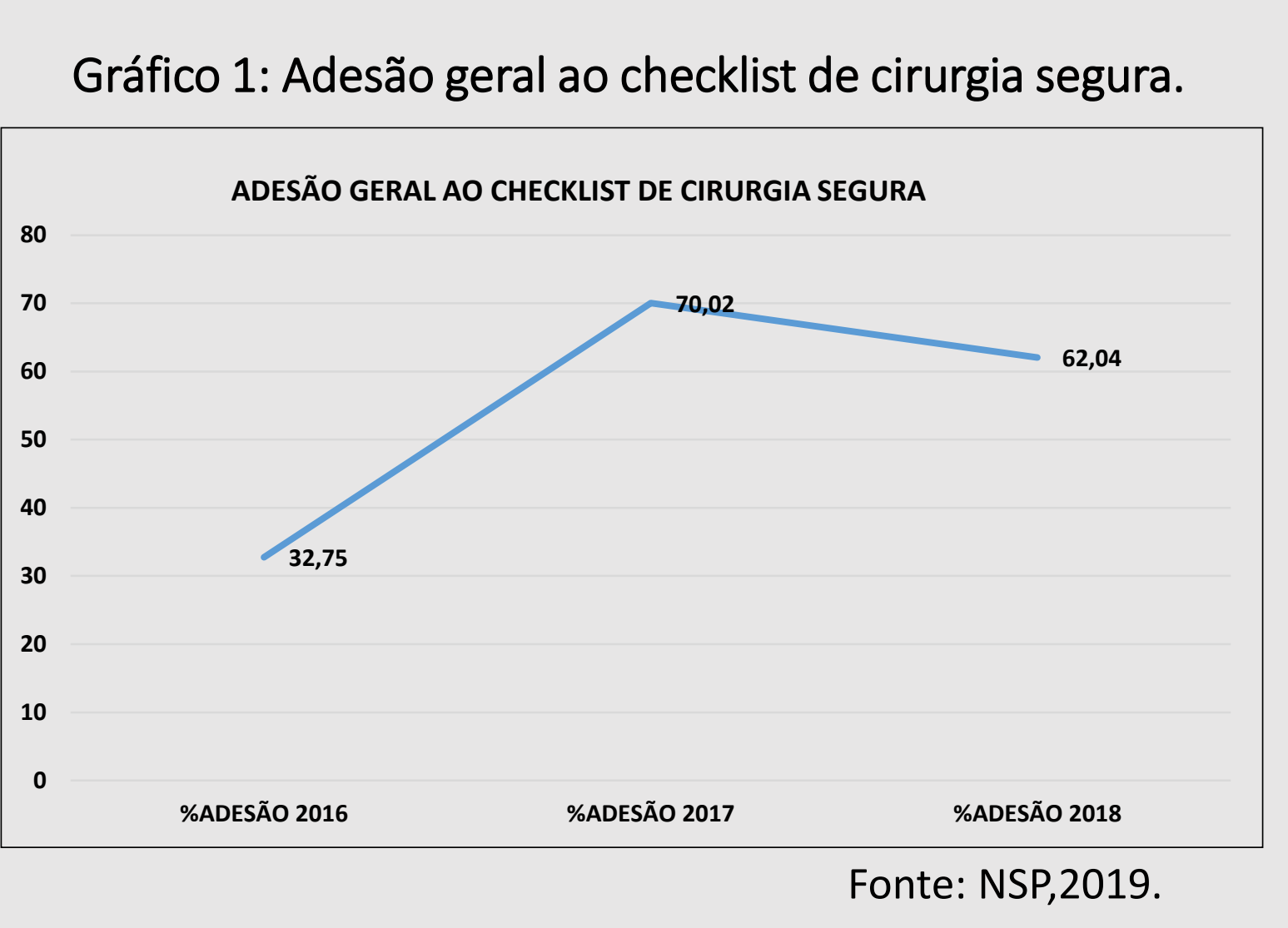

Gráfico 3: Adesão a SAEP

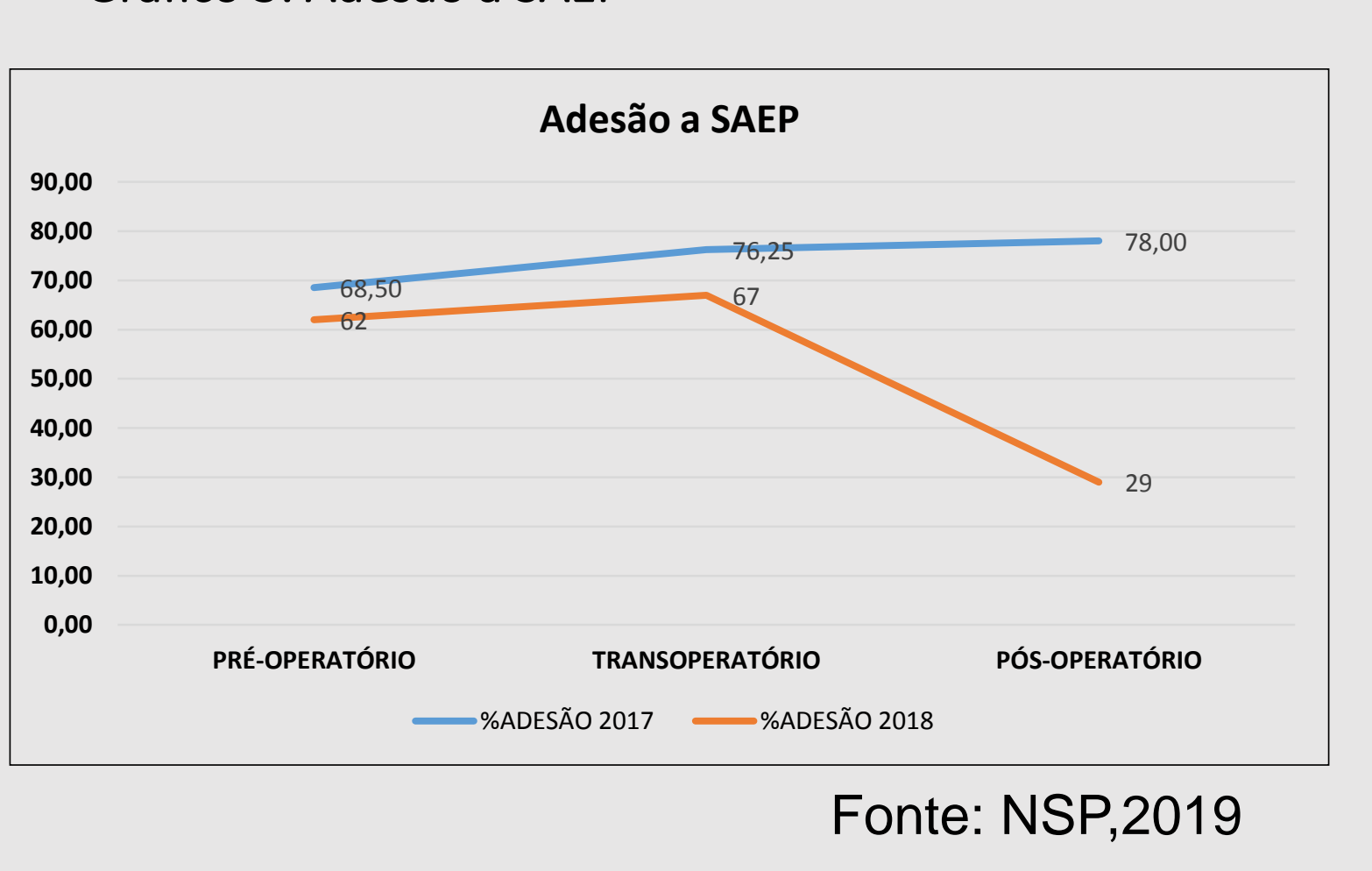

Gráfico 5: Adesão aos itens críticos do checklist de cirurgia segura antes da inducão anestésica.

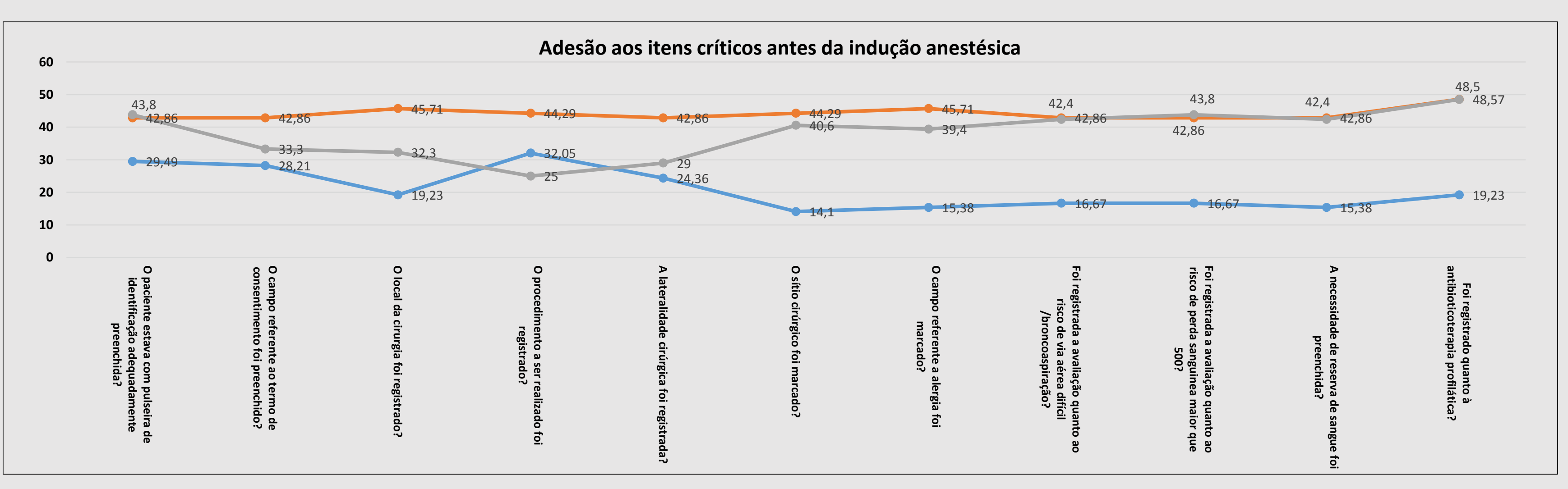

Fonte: NSP,2019

\section{CONCLUSÃO}

A implementação do protocolo teve como principal forca motriz a equipe de Enfermagem e a metodologia utilizada para disseminação do conhecimento sobre segurança foi através de treinamentos e reuniões dentro do espaço de trabalho. O papel da liderança faz diferença e auxilia no sucesso das práticas de cirurgia segura. A educação pelo exemplo é revolucionária.

\section{REFERÊNCIAS}

Organização Mundial da Saúde. Segundo Desafio Global para a Segurança do Paciente: Manual Cirurgias Seguras Salvam Vidas (orientações para cirurgia segura da OMS). Brasília, 2010. Disponível em: www.proqualis.net/seguranca

Brasil. Portaria no 529, de 1ํ de abril de 2013. Institui o Programa Nacional de Segurança do Paciente (PNSP). Diário Oficial da União, 2 abr 2013.

World Health Organization. Conceptual Framework for the International Classification of Patient Safety- Final Technical Report 2009. WHO:Swizterland, 2009 